\title{
Dialogia
}

\section{Letramento e alfabetização de jovens e adultos: um trabalho com gêneros textuais do cotidiano}

\author{
Literacy and reading-writing of young people and adults: working with \\ textual genres of daily life
}

Laís Bastos Marchesoni

Mestre em Educação Universidade Estadual de Maringá - UEM.

Maringá, Paraná - Brasil. lais_marquesoni@hotmail.com

\author{
Elsa Midori Shimazaki \\ Doutora em Educação \\ Universidade do Oeste Paulista - UNOESTE. \\ Presidente Pudente, São Paulo, Brasil \\ Universidade Estadual de Maringá - UEM. \\ Maringá, Paraná - Brasil. \\ emshimazaki@uem.br
}

\begin{abstract}
Resumo: Ao se identificar a necessidade e a relevância de pesquisas sobre os processos de letramento e alfabetização na Educação de Jovens e Adultos (EJA), desenvolvemos o estudo com o objetivo de compreender como a promoção do letramento, nessa modalidade de ensino, via gêneros textuais do cotidiano, desenvolve os processos de leitura e escrita de educandos jovens e adultos em fase de alfabetização. Fundamentados nos pressupostos do letramento e do dialogismo, realizamos a pesquisa com12 educandos que estudam em um programa de EJA, por meio de observações, planejamentos e ações pedagógicas, a utilizar o gênero textual panfleto como instrumento de trabalho. Os resultados da pesquisa apontam a ampliação da alfabetização e do letramento na EJA, por meio de gêneros textuais do cotidiano, a desenvolver os processos de leitura e escrita de educandos jovens e adultos em fase de alfabetização
\end{abstract}

Palavras-chave: Alfabetização e letramento. EJA. Gêneros textuais do cotidiano.

Abstract: Current study analyzes the manner the promotion of literacy through textual genres taken from daily life develops the reading and writing processes of young people and adults within this literacy phase when the needs and relevance of research on literary processes in the Education of Young People and Adults are identified. Foregrounded on literacy and dialogism, current analysis has been undertaken with twelve students enrolled within the program Education of Young People and Adults, through observations, planning and pedagogical activities in which the textual genre 'pamphlet' as a tool is employed. Results showed a broadening of reading-writing and literacy stance by textual genre retrieved from daily life for the development of the readingwriting processes of young and adult students in their literacy course.

Keywords: Schooling and literacy. Education of Young People and Adults. Textual genre from daily life.

Cite como

(ABNT NBR 6023:2018)

MARCHESONI, Laís Bastos; SHIMAZAKi, Elsa Midori. Letramento e alfabetização de jovens e adultos: um trabalho com gêneros textuais do cotidiano. Dialogia, São Paulo, n. 37, p. 1-19, e18218, jan./abr. 2021. Disponível em: https://doi.org/10.5585/dialogia.n37.18218.

American Psychological Association (APA)

Marchesoni, L. B., \& Shimazaki, E. M. (2021, jan./abr.). Letramento e alfabetização de jovens e adultos: um trabalho com gêneros textuais do cotidiano Dialogia, São Paulo, 37, p. 1-19, e18218. https://doi.org/10.5585/dialogia.n37.18218. 


\section{Considerações iniciais}

Ao rever as leis de diretrizes e base da educação brasileira (BRASIL, 1971, BRASIL 1994),constatamos que a educação às crianças é deliberada como prioridade e obrigatoriedade, logo, todas as crianças teriam acesso à escola para aprender os conhecimentos ali oferecidos. Todavia, como aponta Saviani (2013), a escola não foi organizada para receber e ensinar os conteúdos escolares à classe trabalhadora, como consequência, temos alunos que, muitas vezes, frequentam a escola e não se apropriam do conhecimento,também, aqueles que não conseguem concluir os estudos na infância ou, até mesmo, os que nem se adentram à escola. A essas pessoas, o sistema educacional brasileiro oferece a Educação de Jovens e Adultos (EJA), que “[...] constituirá instrumento para a educação e a aprendizagem ao longo da vida” (BRASIL, 2018).

Entendemos que a EJA se tornaria desnecessária se as políticas públicas de educação para crianças e jovens fossem efetivadas a contento. Essa modalidade de educação é uma forma de “devolver" o direito à educação que foi subtraídodas pessoas que não tiveram acesso à escolaridade quando eram crianças. Dessa maneira, a EJA é necessária porque possibilita a aprendizagem, que consideramos um dos instrumentos para a participação interativa na sociedade, assim como a obtençãodos conhecimentos científicos e culturais que a humanidade desenvolveu ao longo da história.

Nesta pesquisa, enfatizamos o processo de alfabetização em jovens e adultos, em sua maioria pertencentes à classe trabalhadora, que não foram alfabetizados quando eram crianças e, depois de adulto ou na terceira idade, têm a necessidade de aprender a ler e escrever para responder às suas demandas sociais cotidianas.

As Diretrizes Curriculares Nacionais da Educação de Jovens e Adultos (DCNEJA BRASIL, 2000) é um dos documentos que respalda a educação de jovens e adultos com pouca ou nenhuma escolaridade.Em seu texto, apresenta que “[...] durante muito tempo houve o domínio da cultura branca, cristã, masculina e alfabetizada sobre a cultura dos índios, negros, mulheres e não alfabetizados, caracterizando-a como uma educação seletiva, discriminatória e excludente" (BRASIL, 2000, p.16). Di Pierro, Joia e Ribeiro (2001, p. 58) afirmam que a EJA “[...] é necessariamente considerada como parte integrante da história da educação em nosso país, como uma das arenas importantes aonde vêm se empreendendo esforços para a democratização do acesso ao conhecimento".As palavras dos pesquisadoresmostram que, depois de duas décadas, ainda lutamos para que todos tenham acesso ao conhecimento e que a escola seja, de fato, para todos os cidadãos. As DNEJA (BRASIL, 2000) apontam para a necessidade da superação do analfabetismo. Apesar de o índice ter diminuído ao longo do tempo,em 2019,ainda tínhamos 6,6\% 
de analfabetos, o que significa cerca de 11 milhões de pessoas que não são capazes de ler e escrever para atender às demandas do cotidiano, como a leitura e a escrita de um bilhete, entre outros gêneros textuais do cotidiano, como demonstra a Pesquisa Nacional por Amostra de Domicílios(IBGE, 2019).

O presente estudotem fundamentação no pressuposto do letramento e do dialogismo,a defender a concepção que a fala e a escrita estão em transformação e interação de uma pessoa com a outra, pois por ela se transmitemopiniões, experiências e conhecimentos. Assim, “Todas as esferas da atividade humana, por mais variadas que sejam, estão sempre relacionadas com a utilização da língua” (BAKHTIN, 2016, p. 279).

A linguagem, para Volóchinov (2018), é essencialmente dialógica, carregada de ideologia e faz parte da vida e penetra nela por meio de enunciados. Ela é escrita por meio de gêneros. Os enunciados abordados por Bakhtin (2016), que compõe os gêneros discursivos, dividem-se em: "O enunciado - oral e o escrito, primário e secundário, em qualquer esfera da comunicação verbal - é individual, e por isso pode refletir a individualidade de quem fala (ou escreve). Em outras palavras, possui um estilo individual" (BAKHTIN, 2016, p. 283). O autor considera os discursos que o homem aprende no espaço e contexto social como um enunciado primário e os conhecimentos elaborados a partir da vivência e práticas culturais, tais como o discurso científico, o romance, as artes, como enunciado secundário.

Após reflexões e constatações sobre a necessidade da discussão do tema, elaboramos a pesquisa aqui relatada, que se justifica e se sustenta pela ausência de estudos que tematizam a alfabetização de jovens e adultos, mediada pelo gênero textual panfleto. Dessa forma, surgiu a questão: Como promover a alfabetização na EJA, de forma que a leitura e a escrita sejam vinculadas às práticas sociais? Para responder à questão, elaboramos o objetivo do trabalho: compreender o processo de alfabetização e letramento na EJA, mediante o emprego de gênero textual do cotidiano social. Para efetivar os objetivos, estudamos a alfabetização e o letramento e elaboramos uma prática pedagógica com alunos, jovens, adultos e da terceira idade, em processo de apropriação da leitura e escrita. Apresentamos a pesquisa, seu delineamento e os resultados, a destacar o uso do gênero textual selecionado, o panfleto, para a ampliação dos processos de alfabetização e letramento de jovens e adultos.

\section{Alfabetização e letramento de jovens e adultos}

As funções psicológicas superioresse desenvolvem mediante várias situações, sejam elas sistematizadas ou não. A apropriação da leitura e da escrita se dá em situações planejadas e 
sistematizadas, a ser uma atividade que exige e desenvolve as funções superiores próprias do homem. A partir dos postulados de Vygotsky, pode-se afirmar que as funções mentais superiores se constituem por meio das relações sociais interiorizadas, já que a organização e as formas das ações são sociais.

Vygotsky (2021) postula que, nas práticas escolares, ao comparar com outras atividades da escola, a leitura e a escrita são restritas, porque desempenham função primordial no desenvolvimento cultural das pessoas. As escolas têm ensinado a desenhar letras e formar palavras, todavia, não têm ensinado abordagens para a fala e a escrita de maneira plena. O autor explica que, “[...] apesar da existência de muitos métodos de ensino de leitura e da escrita, a prática pedagógica ainda não elaborou um meio suficientemente racional, com bases científicas e fundamentada na prática de ensino da escrita às crianças" (VYGOTSKY, 2021, p. 104). Luria (2012) critica a forma como se alfabetiza na escola,ao afirmar que "[...] ensina-se a desenhar letras e construir palavras com ela, mas não se ensina a linguagem escrita. Enfatiza-se a mecânica de ler o que está escrito" (LURIA, 2012, p104.). A escrita é um processo contínuo como uma função psicológica cultural, “[...] o desenvolvimento da escrita depende, em considerável extensão, das técnicas de escrita usadas e equivale essencialmente à substituição de uma técnica por outra" (LURIA, 2012, p. 180).

Odesenvolvimento das funções superiores ocorre, também, por meio da alfabetização.Dessa forma, como aponta Soares (2018, p.52), a preocupação da escola precisa ir além de as crianças, jovens e adultos aprenderem a ler e escrever, poisum indivíduo alfabetizado não é necessariamente um indivíduo letrado, isto é, que sabe fazer uso dos letramentos sociais a envolver leitura e escrita. A autora afirma que o indivíduo letrado é aquele que usa socialmente a leitura e escrita, pratica-as e "responde adequadamente às demandas sociais de leitura e de escrita" (SOARES, 2018, p. 40).

Nessa esteira de pensamento, Tfouni (2010) afirma que o sujeito letrado não precisa ser necessariamente alfabetizado, uma vez que a sociedade tem muitas pessoas analfabetas que conseguem utilizar o dinheiro, narrar fatos e histórias com sequência lógica, tomar ônibus e participar de eventos de letramento.

Britto (2003) alerta para as várias significações do termo letramento. O termo estaria a indicar "as ações políticas-sociais e pedagógicas de formação do sujeito na cultura escrita e a condição em que se encontram indivíduos ou grupos sociais o que lhes permite utilizar competências de ler e escrever para atuar nos espaços sociais organizados em função da escrita" (BRITTO, 2003, p. 52). Letramento se refere, também, à ideia de "alfabetizado, letrado, educado, e supõe o que a pessoa é capaz de fazer com seu conhecimento de escrita" (BRITTO, 2003, p.55). 
Sobre o processo de alfabetização, destacamos que ser alfabetizado vai além de conhecer o código linguístico, ou seja, perpassa o conhecimento das letras do alfabeto, assim, saber decodificar algumas palavras ou frases não é o suficiente para dominar o uso da língua escrita. De acordo com Street, “[...] as práticas letradas permanecem encaixadas em outras instituições” (2014, p.123), dessa forma, o indivíduo já apresenta um repertório de letramento mesmo sem nunca ter frequentado uma escola.

No ambiente escolar, de acordo com Soares (2018), a alfabetização aconteceria concomitantemente ao letramento, que se caracteriza como o uso social da leitura e da escrita. $\mathrm{Na}$ escola, o adulto se desenvolve e adquiri novos conhecimentos com base nos conhecimentos iniciados antes do estudo formal, a vivenciar constantemente os usos sociais da escrita. Assim, o letramento focaliza os aspectos sociais da aquisição de um sistema escrito por uma sociedade (SOARES, 2018).

Defendemos uma proposta de letramento a revelar a insuficiência de apenas alfabetizar o adulto, pois, como cidadão, apresenta um importante repertório de vivências e conhecimentos advindos de suas próprias vivências sociais, que precisam ser consideradas no trabalho educativo. Soares (2018) define as práticas de letramento como “[...] consequência da necessidade de destacar e claramente configurar, nomeando-os, comportamentos e práticas de uso do sistema de escrita, em situações sociais em que a leitura e/ou a escrita estejam envolvidas" (SOARES, 2018, p.98).

O letramento é cultural, ou seja, o educando, ao ser alfabetizado na escola, já apresenta um nível de letramento social anterior, mesmo que em nível inferior ao esperado pelo ambiente escolar. Street (2014) afirma que o nível de letramento social e acadêmico entre os indivíduos são diferentes, já que apresentam um histórico social distinto, assim, o jovem e o adulto quevoltam a estudar, independente dos seus níveis de alfabetização, já adquiriram diversos processos de letramento presentes nos seus cotidianos (STREET, 2014).

Dessa forma, por compreendermos a importância do letramento nas práticas pedagógicas na EJA, realizamos atividades que a englobem no desenvolvimento das ações-pedagógicas. Assim, selecionamos um gênero textual da esfera do cotidiano, o panfleto, na busca de identificação de um gênero que os educandos apresentam maior contato social no seu cotidiano. Bakhtin (2016) emprega a nomenclatura de gêneros do discurso, que se relaciona a enunciados com funções sociais determinadas, com finalidade, interlocução, circulação social e suporte textual definidos.

Marcuschi (2005) afirma que o gênero se elabora coletivamente mediante as atividades do cotidiano que exerce a função de movimento, porque [...] contribuem para ordenar e estabilizar as 
atividades comunicativas do dia-a-dia. São entidades sócio-discursivas e formas de ação social incontornáveis em qualquer situação comunicativa. (MARCUSCHI, 2005, p.19).

Entendemos que o uso de gêneros textuais no processo de alfabetização e letramento aproxima a escola do cotidiano dos alunos. Apresentam uma intenção comunicativa e discursiva imersos no meio social, a retratar as situações de interação verbal e escrita de que fazemos parte diariamente. Utilizamos o termo cotidiano porque trata de gêneros presentes em nosso dia-a-dia, tais como: e-mail, carta, propaganda, notícia de jornal, bula de remédio ou documento oficial para se ter assinatura (OLIVEIRA, 2010).

A convivência sistemática com livros, revistas, jornais, bilhetes, listas, receitas é mais comum e adquirida socialmente, pois as palavras que compõem esses gêneros são expressões de situações já conhecidas pelos educandos. Dessa forma, afirmamos, inicialmente, que o trabalho com gêneros textuais da esfera do cotidiano auxiliaria no processo de alfabetização e letramento de educandos jovens e adultos em processo de alfabetização, o que foi constatado durante a pesquisa conduzida.

Mesmo que o educando adulto ainda não saiba ler e escrever, é importante considerar que convive com as práticas de leitura e escrita diariamente. Soares (2018) discute que todas as pessoas possuem conhecimentos que se caracterizam em distintos níveis de alfabetismo. Dessa forma, os adultos não alfabetizados não desconhecem completamente o sistema de leitura e escrita, a apresentar um nível de letramento mesmo que mais inferior se comparado a outras parcelas da população (SOARES, 2018).

O conceito de letramento é entendido por Silva (2019) como um passo além da aquisição da leitura e da escrita. O letramento é também uma forma de "emancipação e reconstrução social dos sujeitos, visto que as práticas sociais estão trespassadas por relações sociais desiguais e pelos interesses, poder e influência de grupos dominantes nas sociedades” (SÁ; COSTA, 2018, p. 105).

Nuhrich (2005, p. 47) afirma que "[...] a lógica do aprendizado das pessoas jovens e adultas não está baseada em conteúdos, na lógica da escola formal, do simples para o complexo, do fácil para o difícil, mas sim pela lógica da vida e do mundo", ou seja, pelas suas experiências de vida, pois a capacidade de aprender está ligada ao que o sujeito já conhece.

Paiva (2005, p. 460) afirma que "[...] só a mera alfabetização não basta para conferir status deleitor e escritor na realidade dos sujeitos jovens e adultos", a vincular-se a aspectos sociais, políticos, econômicos e culturais, principalmente com significados na vida do educando, ou seja, com o ensino sistematizado com as suas vivências. Sá e Costa (2018, p. 105) reforçam a mesma 
concepção, ao afirmar que “[...] somente a alfabetização dos sujeitos não seria suficiente para garantir-lhes maior voz e inclusão social”.

A alfabetização e a escolarização são tipos de práticas de letramento presentes na família, igreja, trabalho etc. Para Durante (2007) o processo de letramento visa à formação de um indivíduo consciente, crítico e transformador, que participe do poder da língua escrita em sociedade, por isso destacamos a necessidade do letramento para a cidadania e participação efetiva na sociedade letrada.

Sobre o alfabetizar no contexto do letramento, Soares (2018, p. 40) afirma que "[...] o alfabetismo não é apenas um estado ou condição pessoal, é, sobre tudo, uma prática social". É importante considerar que as condições sociais determinam o nível de letramento do indivíduo, a ser considerado no processo de alfabetização.

Ainda é importante destacar a complexidade do processo de alfabetização e letramento. Para Garcia (2004, p. 48) "[...] alfabetizar letrando é o desafio posto para a educação de jovens e adultos", a implicar em um trabalho sistematizado e planejado que abranja os dois processos, indispensável para o êxito da aprendizagem. Nesse sentido, para Silva (2020, p. 10) “As escolas de educação básica enfrentam inúmeros desafios no preparo dos educandos para enfrentar o mundo contemporâneo, informado por infindáveis práticas sociais envolvendo a escrita”, entre elas destacamos a educação de jovens e adultos.

A EJA, no contexto educacional, representa uma possibilidade de acesso à Educação Básica, ao domínio da leitura e da escrita, aos bens sociais e à inserção ao universo letrado (BRASIL, 2000). Assim, concebemos a EJA como uma das possibilidades deinstrumentalização social e de cidadania, já que, mais do que alfabetizar, possibilita a melhoria na qualidade de vida dos indivíduos.

Além disso, a EJA promove autonomia e emancipação, pois a educação em si tem seu caráter libertador. Freire (2019) entende a educação como uma prática da liberdade emancipadora, em que o sujeito consegue se libertar de amarras impostas pela sociedade, como, por exemplo, a falta de conhecimento, a poder, por meio da educação, se tornar mais livre e autônomo (FREIRE, 2019).

Freire (2019) afirma, ainda, que a alfabetização de jovens e adultos é necessária para a emancipação do sujeito, a proporcionar experiência cultural e produção de identidade. De acordo com Garcia (2004, p. 25), “[...] o adulto não retorna à escola com a intenção de recuperar um tempo perdido ou para aprender algo que não aprendeu quando criança. O que ele busca é um aprendizado para as suas necessidades atuais". $\mathrm{Na}$ alfabetização de jovens e adultos, o trabalho com o letramento amplia o sentido de alfabetização, a suprir as necessidades sociais do sujeito. 
Entendemos que o processo de alfabetização proporciona situações de letramento, em que os educandos são colocados em contato com as práticas sociais de leitura, escrita, produção e interpretação de textos variados, com diferentes níveis de dificuldades, em virtude de propósitos igualmente variados, o que buscamos no decorrer da pesquisa. Para tanto, apresentamos a importância do uso de gêneros textuais que possibilite esse desenvolvimento, especificamente com os gêneros textuais do cotidiano.

\section{Método}

A pesquisa faz parte do projeto maior denominado "Linguagem, letramento e diversidade" (UEM), do qual fazemos parte. O projeto de pesquisa foi aprovado pela Comissão Permanente de Ética em Pesquisa para Seres Humanos (COPEP), sob o parecer n. ${ }^{\circ} 56479116.0 .0000 .0104$. Caracterizamos e denominamos esta investigação como uma pesquisa qualitativa e de intervenção pedagógica (DAMIANI, ROCHEFORT, CASTRO, DARIZ, PINHEIRO, 2013). Para tanto, a abordagem qualitativa foi a mais adequada, pois possibilitou a aproximação com os sujeitos da pesquisa, sendo a "[...] metodologia que tem o ambiente natural como sua fonte de dados e o pesquisador como principal instrumento, procura estudar os fenômenos educacionais e seus atores dentro do contexto social e histórico em que acontecem e vivem" (FARIAS, 2010, p. 2).

Os registros de dados foram coletados em uma turma de EJA de uma escola pública do Noroeste do estado do Paraná. A instituição atende ao Ensino Fundamental e tem 30 matriculados na EJA, oferecida no período noturno e de forma presencial

A pesquisa foi pautada na abordagem qualitativa, caracterizada como pesquisa de ação pedagógica. Para compreender melhor o objeto de estudo, buscamos conhecimentos relevantes sobre o tema, ao abordar autores que escrevem sobre ao letramento. Utilizamos como categoria de análise: i) nível de letramento dos alunos; ii) conhecimentos que os educandos possuíam; iii) processos de apropriação da leitura e da escrita.

\section{População de pesquisa}

Participaram do estudo 12 educandos matriculados na EJA, nas turmas de $1^{\circ}$ e $2^{\circ}$ anos do Ensino Fundamental, de acordo com informações obtidas na secretaria da escola. Eram assíduos, característica que observamos nas aulas, também apontado pela professora da turma, além de estarem em fase de apropriação da leitura e da escrita. Também assinaram o Termo de Consentimento Livre e Esclarecido. 


\section{Procedimentos e análises}

O trabalho com os alunos foi realizado por nós, como docentes, durante um ano letivo. Neste texto, relatamos um dos trabalhos com o uso do gênero textual panfleto para odesenvolvimento daalfabetização e do letramento. Utilizamos o panfleto porque é um gênero de circulaçãode fácil acesso aos educandos, presente no dia a dia. Além disso, evidenciamosqueas teorias que fundamentam a presente pesquisa parte do entendimento de que as situações cotidianas modificam o comportamento dos indivíduos e implicam diretamente na sua aprendizagem, por isto, selecionamosum gênero de relevância para o trabalho, para que fosse mais significativo para os alunos envolvidos. A seleção de temas relevantes e atuais, a contemplar diferentes gêneros e níveis de dificuldade de compreensão, que se mostram fundamentais para o aprendizado efetivo.

\section{Trabalho com o panfleto}

Levamos para cada aluno um panfleto de supermercado e apresentamos o seu conteúdo. O trabalho com o panfleto instrumentalizou os participantes da pesquisa para leitura, compreensão e interpretação, pois se caracteriza como uma ferramenta de interação social (OLIVEIRA, 2010).

Discutimos, à princípio, aspectos que envolvem o gênero, tais como sua utilidade, produtos que expõe, valor dos produtos, marcas, dentre outros elementos composicionais. Nesse primeiro momento, os educandos já demonstraram, por meio de relatos, que possuíam uma noção de localização e de localidade referentes ao texto do gênero, ao demonstrar que o panfleto era de mercado mais próximo de suas residências e por eles frequentado. Conheciam outros mercados, compreendiam as diferenças e as concorrências entre os estabelecimentos. Todos os educandos se identificaram com o gênero textual e participaram das atividades propostas. Apesar da pouca escolaridade, possuíam as noções de valor inerente ao gênero, principalmente, reconheciam quando um produto está em oferta, a deixar à mostra noções sociais de letramento (TFOUNI, 2010).

Um dos pontos relevantes da expressão dos educandos é a noção de economia doméstica que apresentam. Comparam preços de produtos com diferentes marcas e reconhecem conceito de oferta e sua importância, dentro do panfleto. Apesar de suas limitações alfabéticas, como a que aparece na fala da"educanda onze" "Não sei ler, mas sei das oferta”, é possível verificar que possui letramento independente da alfabetização. Sobre isso, Street (2014, p. 122) afirma que “[...] existem situações sociais em que o letramento não está associado à escolarização”, como a situação descrita, os processos de leitura e escrita ampliam o nível de letramento, já existente, advindo de experiências cotidianas. 
Ainda sobre economia doméstica, os educandos pesquisávamos preços e controlavam os gastos, o que fica evidente na fala do "educando sete", ao demonstrar interesse pela "carne mais barata", no caso, o frango; da "educanda doze", ao afirmar "mistura é mais caro"; da "educanda um", ao afirmar que: "o ovo é mais barato"; assim como a três, ao relatar que o mais barato é a "salada". Nesse momento, a "educanda dois" discorda da "educanda três" ao afirmar: "apesar que tá 4,50 o tomate", a demonstrar noções de pesquisa de mercado e de economia. Demonstravam, assim, que identificam o valor exato de cada produto, compara-os e apresentam noções de valor, além de aproximações e arredondamentos, como fica explícito na conclusão da "educanda dez" sobre o valor da linguiça de 11,98 ser "quase 12". Verificamos que a fala se transformou em interação à medida que se transmitiu experiências, opiniões e conhecimentos (BAKTHIN, 2016).

Nesses casos descritos, verificamos que noções de economia doméstica e de controle financeiro, que os indivíduos possuíam, foram adquiridos nas suas diferentes interações na comunidade em que estão inseridos e, muitas vezes, para atender às necessidades sociais. Os educandos trabalham e gerenciam suas vidas, recebem dinheiro, fazem compras, pagam contas, o que lhes possibilita viver em uma sociedade em que as demandas da escrita são constantes. Dessa forma, verificamos que, apesar do baixo nível de alfabetização, eles realizam atividades que envolvem os aspectos econômicos e financeiros, o que mais uma vez identifica seu nível de letramento e destaca a importância de um trabalho que contemple a economia doméstica nas práticas escolares, a favorecera sua compreensão e a relação do conhecimento formal com as suas próprias vivências.

Os educandos apresentam noções de uma educação informal, a possibilitar que "[...] qualquer pessoa adquira e acumule conhecimentos, por meio de experiências diárias em casa, no trabalho e no lazer" (BIANCONI; CARUSO, 2005, p. 20). Os educandos estão imersos em uma cultura letrada, e as práticas escolares propiciam que novos conhecimentos sejam construídos a partir daqueles existentes, pois, por meio de conhecimentos do cotidiano, outros são elaborados e ampliados.

Os interessesdas mulhereseram mais voltadosaos produtos de necessidadesbásicas, como arroz, feijão, produtos de limpeza, possivelmente os mais consumidos por elas. A "educanda um" citou o "arroz"; a "educanda dez", o "feijão"; as educandas dois e três, o "amaciante"; o "educando sete", o "feijão e o açúcar"; o “educando cinco", a "cesta básica”, fato que nos faz relacionar às suasreais condições sociais, assim como ao meio econômico em que estão inseridos. Dessa forma, os educandos refletem suas preferências, escolhas e costumes no próprio processo de aprendizagem, o que seria abordado no trabalho pedagógico, pois são conteúdos que aproximam o conhecimento 
científico da realidade do educando, atorná-lo mais significativo.O interesse dos alunos nos fez refletir sobre suas vivências, a verificar que oanalfabetismo e a falta de oportunidades estão relacionados às condições sociais. A escola, nesse contexto, oferece condições de permanência digna e um ensino de qualidade àqueles que a frequentam, a oportunizar melhorias não só educativas, como, também, econômicas e sociais (MORTATTI, 2013).Dessa maneira, refletimos que situações econômicas mais favoráveis, assim como um maior nível de instrução, propiciaria aos indivíduos maiores oportunidades e ampliações de conhecimentos.

Verificamos que os educandos conheciam os alimentos apenas pelas embalagens ou pelos próprios produtos, mas não conseguiam ler o contidoem suas embalagens. Apesar de não lerem, conheciam os produtos e as marcas que estavam no panfleto. Freire (2018, p.16) afirma que a "leitura de mundo antecede a leitura da palavra", pois, apenas pela imagem, conseguiram identificar de qual marca é o produto e ainda opinaram se é de qualidade ou não, isto é considerado como uma decorrência do letramento.

É importante destacar que, mesmo sem ler as palavras contidas no panfleto, os educandos reconhecem as logomarcas, conhecem as cores e as letras que formavam a palavra "Bom Dia", nome do supermercado. Verificamos, assim, a leitura global dos educandos ao identificarmos algumas de suas noções, como ao olharem o panfleto, identificaram o anunciante das ofertas apenas pela logomarca, o que nos leva à constatação de que os educandos apresentam um nível de letramento suficiente para que algumas tarefas cotidianas simples sejam realizadas sem dificuldades, inclusive aquelas que exigem leitura e escrita, advindas de suas práticas e experiências (SOARES, 2018).

Discutimos, também, sobre os produtos do supermercado, a explicar que o panfleto é dividido em categorias, assim como o próprio supermercado. Os educandos citaram as seguintes categorias: "Iimpeza", "bigiene", "frios" e "frutas e verduras". Explicamos que cada "parte" citada representa uma categoria no supermercado e o panfleto também é organizado dessa forma, portanto, aqueles que fazem compras já percebem a distribuição dos produtos em setores do supermercado nas mesmas categorias.

Esse fato reflete o entendimento de uma organização logística já estruturada na sociedade, em que os educandos atuam como consumidores. Observamos que os educandos conhecem os produtos, mas apresentam dificuldades em categorizá-los, compreendem que o refrigerante, a cerveja e o suco são bebidas, porém não conseguem defini-los em uma só categoria, o que ainda exige abstração do conceito (VYGOTSKY, 2008). 
Nessa atividade, fizemos algumas solicitações: circular o feijão; marcar o produto que está à direita e posteriormente à esquerda, acima e abaixo; fazer um círculo no frango em sentido horário e na cerveja no sentido anti-horário; fazer um $\mathrm{X}$ no alimento que mais gosta.

Observamos que os educandos sabem o significado de círculo e de em cima e embaixo, no panfleto impresso. Os desenhos, rabiscos, marcações, pequenos registros que apresentam são integrantes do processo de desenvolvimento da língua escrita (VYGOTSKY, 2007). Por constituírem oportunidades de atribuição de significados a signos sociais, realizados e estimulados com objetivos, facilitam o processo de atribuição de signos aos sons correspondentes da fala o que requer a formação de conceitos, a utilizar o sistema gráfico, no caso letras, sílabas e palavras, para que o educando compreenda a lógica e o funcionamento da escrita.

Os educandos marcaram com facilidade o alimento que mais gostam, a demonstrar suas preferências. Ao circularem o feijão, a "educanda três" comentou que o alimento estava "caro", a evidenciar mais uma vez características de um pensamento letrado.

Nessa atividade, os educandos deram ênfase à pergunta para constatar que estavam a realizar a atividade corretamente, como costumam fazer com a professora regente. $\mathrm{O}$ "educando sete" nos questionou se o comando se referia ao "valor mais baixo", ao referir-se ao produto com o menor valor, então explicamos que o "abaixo" se referia à posição do produto e não ao seu valor. Ao ensinar a diferença entre a escrita e o significado das palavras "baixo e abaixo", o educando demonstrou compreender a explicação.

No caso de noções de direita e esquerda e do sentido horário e anti-horário, os educandos sentiram dificuldade em realizar a tarefa, a necessitar de explicações, pois não tinham ou não dominavam tais noções. Então, explicamos o conceito de direita e esquerda, no panfleto, a demonstrar com partes do corpo e com objetos.

Explicamos que escrevemos as letras e as palavras da esquerda para direita, a demonstrar no quadro de giz como isto acontece. As educandas dois e doze, que já nomeavam as letras corretamente, disseram: "Isso é fácil". Já o "educando seis" deu um exemplo ao afirmar que a mão esquerda é "a mão da aliança". A "educanda dois" relatou ter aprendido essas noções "quando faz̧ia auto escola", a demonstrar ter aprendido a lateralidade no seu cotidiano. Verificamos que os educandos dão significado ao conceito por meio de mecanismos próprios, como a "mão da aliança" ou o "lado do volante", a facilitar sua compreensão.,

Para a explicação de noções de horário e anti-horário, mostramos como é o sentido dos ponteiros do relógio e pedimos que os educandos fizessem com a mão o sentido horário. Refizemos todo processo novamente para explicar o sentido anti-horário. Demonstramos também 
os sentidos da lateralidade na escrita das letras, por meio do traçado escrito das vogais, para demonstrar o sentido que a escrita apresenta em cada uma delas.

Vygotsky (2007) considera como pré-história da linguagem escrita rabiscos, desenhos, jogos, brincadeiras etc., que são “[...] momentos iniciais do desenvolvimento da língua escrita que, ao atribuir a objetos a função de signos, o sujeito constrói sistemas de representação, precursores e facilitadores da compreensão do sistema de representação que é a língua escrita" (VYGOTSKY, 2007, p.120). Por isso, o objetivo da atividade foi ampliar as possibilidades de compreensão do sistema da língua escrita. Por meio dela, verificamos que, ao se ter maior noções de direção e espaço, mais facilidade na escrita os educandos demonstram, pois apresentam um traçado mais correto e elaborado das letras e uma noção de escrita mais ampla (VYGOTSKY, 2007).

Para tanto,primeiramente, registramos no quadro as letras do alfabeto, a explicar a correspondência entre fonema e grafema. Os educandos pronunciaram as letras e demonstraram conhecê-las, ficando em silêncio apenas nas letras $\mathrm{Y}$ e W, por serem menos utilizadas nas atividades escolares e nos seus cotidianos. Luria (2012) argumenta que a escrita começa antes de a pessoa entrar nas escolas. Soares (2018) aponta que a aquisição do sistema de escrita tem início antes mesmo de o sujeito ser introduzido ao ensino formal. Assim, os educandos pesquisados já têm contato com as letras e apresentam conhecimentos, mesmo antes da vida escolar, muitas vezes, a nomeá-las e reconhecê-las em suas grafias.

Em seguida, questionamos os educandos sobre quais letras do alfabeto eram marcadas como as vogais.Dois deles responderam corretamente, os demais não se manifestaram. A “educanda doze" disse que já tinha "ouvido falar", mas que não lembrava o que era. Então, dividimos os grupos de vogais e consoantes, apresentamos oralmente e com a escrita no quadro de giz.

Propusemos, então, uma atividade em que os educandos identificassem as vogais e as consoantes no panfleto de supermercado. A atividade possibilitou a retomada dos conceitos sobre alfabeto, vogais e consoantes, a reelaborar o conceito de escrita e som das letras, a considerar que os educandos estão em relação permanente com as palavras no seu cotidiano.

Em outra atividade, solicitamos que procurassem produtos de uma mesma categoria eleitos por eles e escrevessem seus nomes. Com essa atividade, constatamos que a escrita apresenta uma falta de correspondência com a imagem, ou seja, os educandos não leem o produto antes de registrar ou depois do registro, a cometer desvios de escrita, como, por exemplo, na atividade da educanda "um", que registrou a palavra "sãbaepo", ao se referir a sabão em pó, a reproduzir a sua própria fala, a trazer, para a escrita, marcas da oralidade. Também escreveu "desinfetante", 
separando as sílabas "desi-fetante", por acreditar que a palavra é composta. Trocou o S pelo Z e escreveu de forma espelhada, a representar uma dificuldade ortográfica.

A escrita reflete a fala, de acordo com a própria oralidade, por estar no processo de aquisição da leitura e devido às marcas de oralidade, os educandos não percebem os desvios na escrita, consequentemente não os corrigem. Cagliari (1982) discorre como os diferentes "modos de falar" influenciam na escrita, define-os como "[...] dialetos em uso, que são consequência da diversidade de classes sociais, capacidade econômica, origem regional etc.” (CAGLIARI, 1982, p.78). Dessa forma, constatamos que os educandos, muitas vezes, escrevem como falam, trazendo diferentes marcas da oralidade para a escrita. Para Albuquerque, Leal e Morais (2010), há um anseio em aprendera falar corretamente, pois, na sociedade, a forma de falar também confere posição social e os educandos revelaram, em algumas situações, sentirem vergonha em "falar errado", a sentirem-se excluídos e marginalizados em diversas situações cotidianas em que necessitam da oralidade.

Ainda sobre a escrita, algunseducandos escreveram palavras repetidamente, porque havia,no panfleto,dois produtos com a mesma função, mas com marcas diferentes, a revelar que ainda não apresentam o conceito estabelecido. Isto aconteceu com a educanda “dois", na categoria de produtos de limpeza, em que registrou duas vezes o limpador, por haver dois produtos com marcas diferentes. Em relação às categorias, os educandos não estabeleceram a diferença entre carnes e embutidos, pois também registraram as palavras mortadela e salsicha, a demonstrarnão ter subdividido o conceito.

Durante a realização da atividade, auxiliamos os educandos na compreensão da divisão das categorias semânticas, no registro dos produtos e na escrita das palavras ao surgir algumas dúvidas, como da educanda "quatro", que nos questionou o uso do dígrafo CH na palavra "salsicha". Ao pronunciarmos a palavra para a educanda escrever, questionou se a sílaba CHA era escrita com X, ao que explicamos a forma correta da língua padrão, a aluna compreendeu e a escreveu adequadamente. Assim fizemos com os demais educandos durante a atividade. É importante destacar que algumas características da escrita dos educandos, como as citadas, fazem parte do próprio processo de alfabetização e dos níveis que os educandos se encontram, como é o caso das trocas de letras observadas nas atividades.

Os educandos estavam em fase de apropriação da escrita, por isso, para a execução da atividade, utilizaram o panfleto como recurso, a procurar os produtos da mesma categoria pela imagem e escrever por meio da sua descrição. Alguns escreveram sem se atentar com a quantidade de letras e com quais letras deviam escrever, ou com a diferença que há entre letras e sons, uma 
vez que ainda não compreendiam a escrita como uma possível representação da fala e não estabeleciam a relação entre grafemas e fonemas, sem perceber os sons das sílabas e não atribuir, a cada sílaba, as letras que a compõe, o que se constata na fase que se encontravam.

Sobre o processo de leitura, apenas quatro educandos leram algumas palavras de forma lenta e silabada, muitas vezes, não conseguindo lê-las completa e adequadamente. Os educandos,de uma forma geral, demonstram ter maior facilidade na escrita do que na leitura. Neste processo, a interação do professor é primordial, a demonstrar, explicar, auxiliar o processo para que a alfabetização se efetive.

Ao analisarmos o uso do panfleto, destacamos o envolvimento e o interesse dos educandos, por ser um gênero textual conhecido, poia as atividades com base nele se tornaram mais significativas e propiciaram um maior aprendizado sobre os produtos contidos, assim como a ampliação de noções de economia. Street (2014) discorre que o conhecimento utilizado no cotidiano dá significado social à leitura e à escrita, assim como nas atividades descritas.

Nesse caso, com o panfleto de supermercado, mesmo não lendo alfabeticamente, o contato com a língua escrita proporcionou maior nível de entendimento.

Durante a pesquisa, verificamos alguns processos de funções psicológicas superiores, como a capacidade de planejamento e a atenção para executar a atividade, a lembrança e a memorização para responder às questões que se desenvolvem na relação entre os indivíduos no contexto sóciohistórico mediadas por instrumentos e signos (VYGOTSKY, 2008). Além de os educandos demonstrarem ter conhecimento espontâneo sobre o assunto, por meio da atividade sistematizada, ampliaram as habilidades de leitura e escrita, assim como o nível de letramento.

As produções e as discussões nos permitem afirmar que os educandos apresentam uma leitura de mundo a partir de um bom nível de letramento. Tfouni (2010) afirma que, mesmo os sujeitos que não dominam a escrita e a leitura apresentam um nível de letramento adquirido em situações cotidianas, como no caso de ir ao supermercado. As respostas e as discussões mostram que o panfleto é um gênero textual cotidiano utilizado e conhecido por todos, principalmente por ser um meio com informações visuais explícitas ao leitor. Dessa forma, o gênero textual cumpriu sua função social, que é a de informar sobre produtos, valores e ofertas do supermercado.

Por meio desse gênero, os educandos ampliaram as noções sobre a utilidade do panfleto de supermercado, entenderam sua função e os elementos que compõem a sua estrutura composicional, o seu uso cotidiano, a evidenciar seu nível de letramento. As atividades com base no panfleto atingiram o objetivo inicial da pesquisa, ao demonstrar a importância do uso de gêneros 
textuais do cotidiano na promoção da alfabetização e do letramento de jovens e adultos em fase de alfabetização.

\section{Considerações finais}

Compreender a relação entre alfabetização e letramento é imprescindível para que se possa construir práticas efetivas de leitura e escrita. O desenvolvimento da presente pesquisa possibilitou uma análise sobre o tema alfabetização e letramento na educação escolar de jovens e adultos. Os resultados demonstram que a aprendizagem ocorre em qualquer momento do desenvolvimento humano, sendo assim, não se aprende apenas quando é criança, pois não há uma idade adequada para se aprender.

Ao longo da pesquisa, constatamos a importância do tema em que nos propusemos a investigar, pois, na sociedade letrada em que vivemos, saber escrever o nome ou ler um bilhete simples não garante ao sujeito a participação social.

Ao estudarmos alfabetização e letramento, exploramos diferentes conceitos em uma pesquisa bibliográfica que abrangeu o letramento e a teoria dialógica do Círculo deBakthin, assim como aqueles que fundamentam suas pesquisas nos pressupostos dessa corrente teórica. Também especificamos o processo de alfabetização e letramento de jovens e adultos, o que reafirmam os pressupostos que amparam esta pesquisa, ao afirmarem que alfabetização e letramento são interligados no trabalho educativo, inclusive para jovens e adultos.

As ações pedagógicas nos proporcionaram uma revisão teórica com o tema da pesquisa e maior contato com os educandos da EJA a serem imprescindíveis para que chegássemos às análises e aos resultados com mais propriedade. Assim, buscamos utilizar conteúdos vinculados ao cotidiano dos educandos e de suas práticas sociais em um trabalho concomitante de alfabetização e letramento, a permitir sempre trazer os conhecimentos da esfera do cotidiano para a promoção do nível do letramento, consequentemente, da alfabetização.

A forma como organizamos e conduzimos as ações pedagógicas foi fundamental para a os resultados, pois as atividades planejadas tiveram como respaldo práticas de leitura e escrita, concomitante ao letramento e às vivências dos educandos. $\mathrm{O}$ trabalho com o gênero textual da esfera do cotidiano tornou o ensino mais significativo e consequentemente promoveu maior aprendizado aos envolvidos.

A participação efetiva dos educandos em várias práticas e interações sociais foi de extrema importância, uma vez que todos demonstraram desenvolvimento nas atividades propostas, mesmo de forma e em níveis diferentes. Por meio das ações pedagógicas, promovemos o uso efetivo de 
escrita proveniente do letramento, pois, para nós, o aprendizado da leitura e da escrita só é efetivo se estiver enraizado às práticas sociais de leitura e escrita, por isso, tivemos a preocupação de que o gênero textual utilizado estivesse contextualizado socialmente e fosse significativo para os educandos.

O objetivo da pesquisa foi alcançado, constatamos que, ao inserir o educando na prática de leitura e escrita por meio de um gênero textual que tivesse contato, como é o caso do panfleto, articulamos, de forma simultânea, a alfabetização e o letramento, o que propiciou maior desenvolvimento e efetividade na aquisição dos processos de leitura e de escrita.

Como resultados da pesquisa, constatamos: i) a compreensão da importância da relação das práticas pedagógicas e dos procedimentos metodológicos da EJA estarem alinhados às vivências dos educandos: ii) os avanços na alfabetização e no letramento dos alunos; iii) os adultos considerados analfabetos possuem letramento; vi) a necessidade de propiciar situações de escrita que se assemelham às situações vivenciadas fora da escola, desde que sejam significativas e garantam a formação de leitores plenos em sociedade; v) os gêneros textuais da esfera do cotidiano são ferramentas que auxiliam nos processos de alfabetização e de letramento de jovens e adultos.

A pesquisa expõe uma contribuição para a área da Educação, a demonstrar avanços no processo de alfabetização e letramento dos educandos inseridos na EJA, por meio de gêneros textuais utilizados em seu cotidiano.

\section{Referências}

ALBUQUERQUE, E. B. C.; LEAL, T. F.; MORAIS, A. G. Alfabetizar letrando na EJA. Belo Horizonte: Autêntica Editora, 2010.

BAKHTIN, M. Os gêneros do discurso.São Paulo: Editora 34, 2016. 176p.

BIANCONI, M. L.; CARUSO, F. Educação não formal. Ciência \& Cultura, São Paulo, v. 57, n.4, p.1-20, 2005.

BRASIL. Lei 5.692 de 11 de agosto de 1971. Brasília: Ministério da Educação. Disponível em: http:// www.planalto.gov.br/ccivil_03/Leis/L5692.htm. Acesso em: 07 abr. 2021.

BRASIL. Lei ñ. 9394/1996 Brasília: Ministério da Educação, 1996.

BRASIL. Lei ñ 13.632/2018. Brasília: Ministério da Educação http://www.planalto.gov.br/ccivil_03/_Ato2015-2018/2018/Lei/L13632.htm\#art1. Acesso em 01 abr. 2021.

BRASIL. Parecer CNE 11/2000: Diretrizes Curriculares Nacionais para a Educação de Jovens e Adultos. Brasília: Câmara de Educação Básica, 2000. 


\section{Dialogia}

MARCHESONI, Laís Bastos; SHIMAZAKi, Elsa Midori. Letramento e alfabetização de jovens e adultos: um trabalho com gêneros textuais do cotidiano

BRITTO, L. P. L. Sociedade da cultura escrita, Alfabetismo e participação. In: RIBEIRO, V. M. (Org.). Letramento no Brasil. São Paulo: Global, 2003, p. 47-64.

CAGLIARI, L. C. Textos espontâneos na primeira série: evidência da utilização, pela criança, de sua percepção fonética para representar e segmentar a escrita. Cadernos Cedes, São Paulo, v. 14, p. 25-29, 1982.

DAMIANI, M. F., ROCHEFORT R. S., CASTRO, R. F. de, DARIZ, M. R., PINHEIRO, S. S. Discutindo pesquisas do tipo intervenção pedagógica. Cadernos de Educação, n.45, p. 57-67, 2013.

DI PIERRO, M. C.; JOIA, O.; RIBEIRO, V. M. M. Visões da educação de jovens e adultos no Brasil. Cadernos CEDES, Campinas, v. 21, n. 55, p. 58-77, nov. 2001.

DURANTE, M. Alfabetização de adultos: Leitura e Produção de Textos. Porto Alegre: Artmed, 2007.

FARIAS, A. F. Identificando os sujeitos da Educação de Jovens e Adultos no município de Presidente Prudente - SP. In: Anais do Congresso de iniciação científica da UNESP, Anais. São José do Rio Preto, 2010.

FREIRE, P. Pedagogia do oprimido. Campinas: Cortez, 2019.

FREIRE, A importância do ato de ler. São Paulo: Cortez, 2017.

GARCIA, I. H. M. Jovens e adultos em processo de alfabetização: voz e vida, revelações e expectativas. Niterói: Universidade Federal Fluminense, 2004.

IBGE. Pesquisa Nacional por Amostra de Domicílios Contínua. Notas técnicas: Versão 1.5, Rio de Janeiro: IBGE, 2019.

LURIA, A. R. O desenvolvimento da escrita na criança. In: VYGOTSKY, L. S.; LURIA, A. R.;

LEONTIEV, A. N. (Org.) Linguagem, desenvolvimento e aprendiragem. São Paulo: Ícone, 2012, p.143189.

MARCUSCHI, L. A. Gêneros textuais: definição e funcionalidade. In: DIONISIO, Ângela Paiva;

MACHADO, A. R.; BEZERRA, M. A. (Org.). Gêneros textuais e ensino. Rio de Janeiro: Lucerna, 2005, p. 19-36.

MORTATTI, M, R, L.Alfabetização no Brasil: uma história de sua história. Marília: Cultura Acadêmica, 2013.

NUHRICH, S. L. Educação de pessoas jovens e adultas: Um olhar investigativo sobre uma proposta curricular. Joinville: UNIVALI, 2005.

OLIVEIRA, M. S. Gêneros textuais e letramento. Revista Brasileira de Linguística Aplicada. Belo Horizonte, v. 10, n. 2, p. 325-34, abr.jun.2010. 


\section{Dialogia}

MARCHESONI, Laís Bastos; SHIMAZAKi, Elsa Midori. Letramento e alfabetização de jovens e adultos: um trabalho com gêneros textuais do cotidiano

PAIVA, J. Educação de Jovens e Adultos: direito, concepções e sentidos. Tese de Doutoramento em Educação. Programa de Pós-Graduação em Educação da Universidade Federal Fluminense. Niterói: UFF, 2005.

SÁ, E. M.; COSTA, E. J. Abordagem comunicativa e letramento crítico: pontos de convergência para a inclusão de práticas digitais no contexto brasileiro de ensinoaprendizagem.Letras \& Letras, v. 34, n. 1, p. 95-121, jul. 2018

SAVIANI, D. Pedagogia histórico-crítica: primeiras aproximações. Campinas: Autores Associados, 2013

SILVA, W. R. Polêmica da alfabetização no Brasil de Paulo Freire. Trabalhos em Linguística Aplicada, v. 58, n. 1, p. 219-240, 17 abr. 2019.

SILVA. Letramento e Fracasso escolar: o ensino da língua materna. Manaus: Editora UEA, 2020.

SOARES. Alfabetização e Letramento. São Paulo: Contexto, 2018.

STREET, B. Letramentos sociais. São Paulo: Parábola Editorial, 2014.

TFOUNI. Letramento e alfabetização. São Paulo: Cortez, 2010.

VOLÓCHINOV, V. Marxismo e filosofia da linguagem. São Paulo: Editora 32, 2018.

VYGOTSKY, L. S. A formação social da mente. São Paulo: Martins Fontes, pp.119-34. 2007.

VYGOTSKY, L. S. Pensamento e linguagem.4. ed. São Paulo: Martins Fontes, 2008.

VYGOTSKY, L. S. Psicologia, educação e desenvolvimento. São Paulo: Expressão Popular, 2021. 